\title{
Sensitivity of radiative properties of persistent contrails to the ice water path
}

\author{
R. R. De León ${ }^{1}$, M. Krämer ${ }^{2}$, D. S. Lee ${ }^{1}$, and J. C. Thelen ${ }^{3}$ \\ ${ }^{1}$ Dalton Research Institute, Manchester Metropolitan University, UK \\ ${ }^{2}$ Forschungszentrum, Jülich Institut für Energie und Klimaforschung Stratosphäre, Germany \\ ${ }^{3}$ Met Office, Exeter, UK \\ Correspondence to: R. R. De León (r.deleon@mmu.ac.uk)
}

Received: 13 April 2011 - Published in Atmos. Chem. Phys. Discuss.: 13 July 2011

Revised: 26 July 2012 - Accepted: 13 August 2012 - Published: 5 September 2012

\begin{abstract}
The dependence of the radiative properties of persistent linear contrails on the variability of their ice water path is assessed in a two-stream radiative transfer model. It is assumed that the ice water content and the effective size of ice crystals in aged contrails do not differ from those observed in natural cirrus; the parameterization of these two variables, based on a correlation with ambient temperature derived from in situ observations, allows a more realistic representation than the common assumption of fixed values for the contrail optical depth and ice crystal effective radius.

The results show that the large variability in ice water content that aged contrails may share with natural cirrus, together with an assumed contrail vertical thickness between 220 and $1000 \mathrm{~m}$, translate into a wider range of radiative forcings from linear contrails $\left[1\right.$ to $66 \mathrm{~m} \mathrm{Wm}^{-2}$ ] than that reported in previous studies, including IPCC's [3 to $30 \mathrm{~m} \mathrm{Wm}^{-2}$ ]. Further field and modelling studies of the temporal evolution of contrail properties will thus be needed to reduce the uncertainties associated with the values assumed in large scale contrail studies.
\end{abstract}

\section{Introduction}

Contrail radiative studies generally assume a fixed particle size distribution (PSD) in the ice cloud (e.g., Strauss et al., 1997; Meerkötter et al., 1999; Minnis et al., 1999) and a fixed optical depth (OD) (e.g., Minnis et al., 2004; Stuber and Forster, 2007; Rädel and Shine, 2008). This simplification is made in response to the large uncertainties in the characterization of ice cloud PSDs (e.g., McFarquhar et al.,
2007; Jensen et al., 2009) and the large variability found in ice cloud micro- and macro-physical properties, which must be taken into account when deriving representative values for large scale contrail simulations.

In most radiative transfer applications ice clouds are represented by two parameters, namely their ice water content (IWC) and a metric of their size spectrum, such as the effective radius or Fu's generalized size parameter (Fu, 1996). Contrail crystals may differ, both in shape and concentration, from those observed in natural cirrus under the same conditions (Poellot et al., 1999); how much the physical properties of these crystals are determined by their anthropogenic origin and how much by the atmospheric environment is not clear (e.g. Jensen and Toon, 1997; Schumann et al., 2011). Recent measurements, such as those from the mid-latitude field campaign CIRRUS III (Schäuble et al., 2009) have shown that the ice water contents in cirrus and aged contrails are similar under the same atmospheric conditions, while ground-based observations of an aged contrail made by Atlas and Wang (2010) have confirmed that the IWC of linear contrails can reach values close to the upper limit for mid-latitude cirrus.

More extensive contrail field measurements are needed but, given the small differences between the IWC in natural cirrus and in aged contrails at the same temperature in nonconvective regions and the fact that the radiative forcing (RF) of ice clouds is mainly determined by their ice water path, it seems reasonable to use a characterization based on cirrus measurements to represent the developed stages of contrails, as has been done previously (e.g., Wyser and Ström, 1998; Ponater et al., 2002). 
In order to investigate the sensitivity of the global RF of persistent linear contrails to such an assumption, we set up a model with a pre-defined contrail coverage distribution fixed at a given altitude but using a representative range of physical depths. We estimate the effect of this layer on the local and global radiation fields, allowing its ice water content and effective ice crystal size to vary as a function of ambient temperature.

\section{Model simulations}

The physical properties of both, aged contrails and natural cirrus are prescribed in the model simulations using Schiller et al.'s (2008) IWC climatology and the PSD parameterization of McFarquhar and Heymsfield (1997), based on ice cloud observations in the tropics covering a temperature range from $-20^{\circ}$ to $-70^{\circ} \mathrm{C}$.

The range of observed cirrus IWCs compiled by Schiller et al. is represented in Fig. 1 (top), with fitted curves being shown for minimum, mean, and maximum measured values (dotted, solid and dashed black lines, respectively) as functions of temperature. It is important to mention that the cases linked to convective regions are not included in the fits. These fits are used as input in McFarquhar and Heymsfield's PSD parameterization at six temperature values, covering a range from 195 to $245 \mathrm{~K}$, to produce 18 PSDs. The generalized size $\left(D_{\text {ge }}\right)(\mathrm{Fu}, 1996)$ calculated for these distributions ranges from 11 to $75 \mu \mathrm{m}$. The 6 PSDs corresponding to the mean IWC fit, are plotted in Fig. 1 (middle) as functions of the particles' equivalent-volume diameter.

The single scattering properties (extinction coefficient, single scattering albedo, and asymmetry parameter) of ice crystals, modelled as randomly oriented hexagonal prisms, are integrated over the 18 PSDs and parameterized in terms of their IWC and $D_{\mathrm{ge}}$ : such a hexagonal prism habit matches both the total volume and projected areas retrieved by McFarquhar and Heymsfield, making the micro-physical and the optical properties in the model consistent. The databases of the optical properties for other habits currently available to us did not fulfill this consistency requirement. We therefore only use hexagonal prisms in our modelling. The methodology presented in Fu et al. (1998) is used to integrate the long-wave (LW) optical properties calculated by Baran et al. (2001). In the shortwave (SW), the parameterization described by $\mathrm{Fu}$ (1996) and the single scattering properties calculated by Yang et al. (2000) are applied. The SW and LW parameterizations are incorporated into the Edwards and Slingo two-stream radiative transfer model (Edwards and Slingo, 1996) with a configuration of 6 and 9 bands in the $\mathrm{SW}$ and in the LW spectral regions, respectively.

The uncertainties in the characterization of the relative abundance of small crystals may affect the calculated radiative properties of ice clouds (McFarquhar et al., 2007). In order to ensure an accurate representation of the relative con-
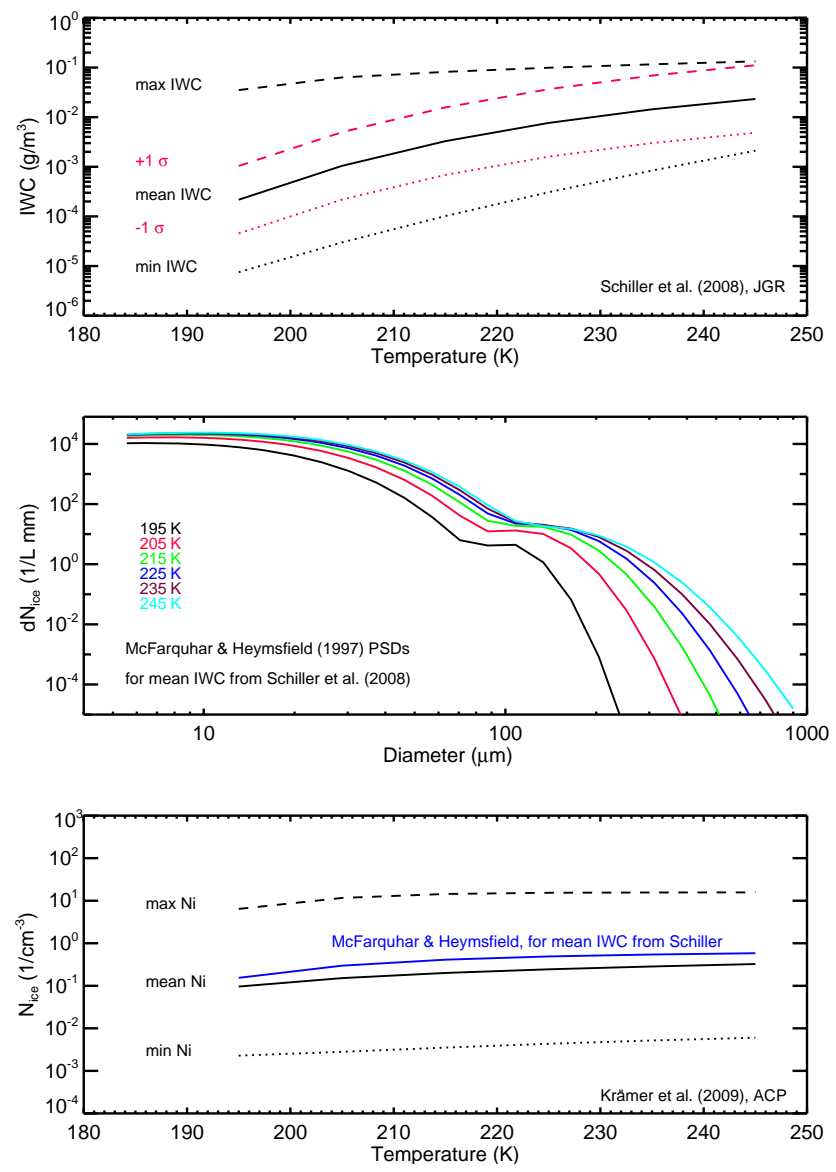

Fig. 1. Top: Minimum, mean, and maximum IWC fits from Schiller et al., the red lines correspond to one standard deviation. Middle: Particle number densities as a function of equivalent-volume diameter, based on McFarquhar and Heymsfield's parameterization and Schiller et al.'s mean IWC. Bottom: Minimum, mean, and maximum total ice crystal numbers observed by Krämer et al. (2009) compared to the total ice crystal number for mean IWC in the present study, shown in blue.

centration of small particles in the model, the total ice number concentrations used here are compared with those compiled by Krämer et al. (2009), who provide quality-checked aircraft in situ observations of ice crystal numbers performed during 28 flights in tropical, mid-latitude and Arctic field experiments, covering latitudes from $20^{\circ}$ South to $75^{\circ}$ North. The comparison (Fig. 1, bottom) suggests that despite the fact that McFarquhar and Heymsfield's PSDs are limited to one campaign, the dependence of the relative small crystal concentration on temperature is consistent with values retrieved at a wide range of latitudes.

The background meteorology used in the model is based on monthly climatological data for water vapour, ozone, temperature, and surface albedo from ECMWF (Simmons and Gibson, 2000). Three-dimensional distributions of low, middle and high cloud cover, and cloud total water path from the International Satellite Cloud Climatology Project (ISCCP) 
D2 (Rossow and Schiffer, 1999) are used. These cloud fields are monthly averages of ISCCP's three-hour resolution data. interpolated to a $2.5^{\circ} \times 2.5^{\circ}$ regular latitude/longitude grid and 23 layers in the vertical, extending up to $1 \mathrm{hPa}$. The total water paths of all clouds from ISCCP are scaled linearly in order to obtain a cloud SW RF in reasonable agreement with satellite estimates. An increase of $80 \%$ of the total water paths from ISCCP results in a global annually averaged SW cloud RF of $47.7 \mathrm{Wm}^{-2}$ (otherwise, $37.4 \mathrm{Wm}^{-2}$ ), which compares well with the estimate of $48 \mathrm{Wm}^{-2}$ from the Earth Radiation Budget Experiment (ERBE) mission (Li and Leighton, 1993).

The total water paths and top of the cloud information from ISCCP are used to define the total water contents in the model's vertical resolution. The cloud's phase is prescribed as ice-only at temperatures below $-39^{\circ}$ and liquidonly above $-10^{\circ} \mathrm{C}$; between these two temperatures, the solid component is prescribed by Schiller et al.'s climatology, while the liquid content is defined as the residuum difference between the total and the solid phase. The $D_{\mathrm{ge}}$ of the solid phase is prescribed as a function of the IWC and temperature of the cell according to McFarquhar and Heymsfield's parameterization. For the liquid cloud phase, spherical droplets with an effective radius of $10 \mu \mathrm{m}$ are assumed. The vertically integrated 2-D contrail cover (CC) distribution is taken from Fichter et al. (2005) who, based on the TRADEOFF inventory of aircraft flown distance for the year 1992, found an annual mean global cover of $0.047 \%$.

It is assumed in our radiative transfer calculations that clouds in adjacent layers are maximally overlapped, while groups of clouds separated by one or more clear layers are randomly overlapped ("maximum-random overlap"). The shortwave (SW), long-wave (LW) and net (SW+LW) instantaneous RFs are calculated at the top of the atmosphere for two representative months, January and July. The solar zenith angles and day lengths at the middle of the month are used to represent the month's SW average. The diurnal cycle is approximated by a Gaussian integration of 5 solar zenith angles. No diurnal dependence is assumed on the CC extent, as no global estimate of contrail lifetimes is available at present.

In the simulations, unless stated otherwise, mean observed IWC values from Schiller et al. for non-convective cirrus are prescribed at the centre of a $1000 \mathrm{~m}$ thick contrail layer positioned at $200 \mathrm{hPa}(\sim 38000 \mathrm{ft})$ with a realistic horizontal cover for year 1992. Given the impossibility in our model to allocate in the same cell two different IWC values, in the cells in which natural cirrus and contrail coincide, the value for cirrus is prescribed in the cell while the contrail's ice mass, defined by the assumed IWC regime and physical depth, is emulated by rescaling the contrail's horizontal extent.

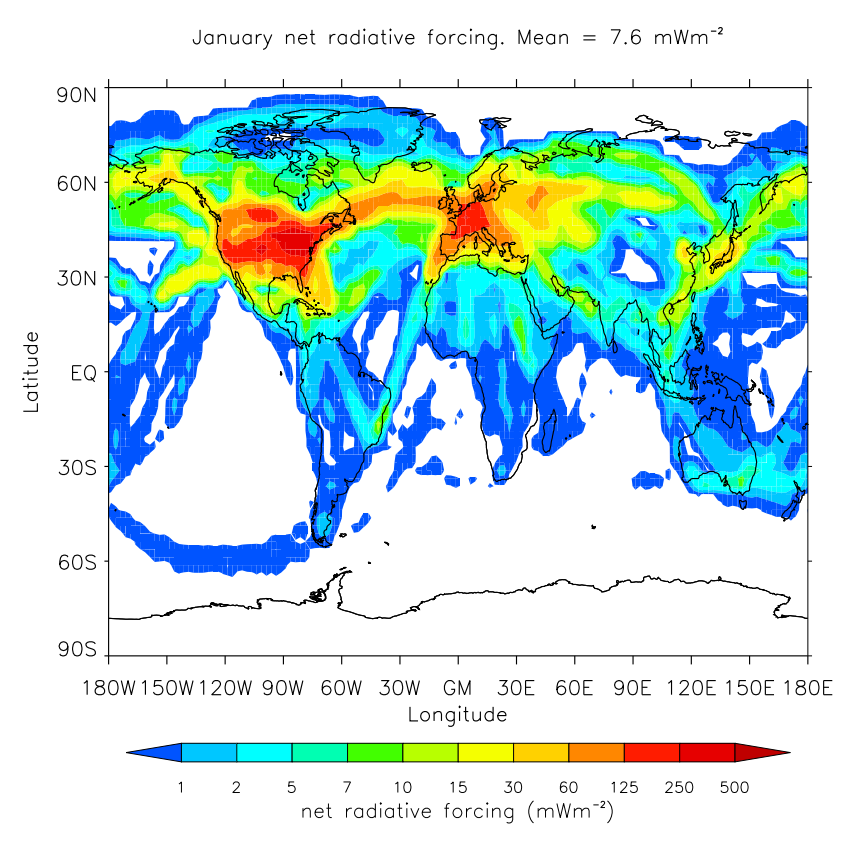

Fig. 2. Net January contrail radiative forcing for mean IWC.

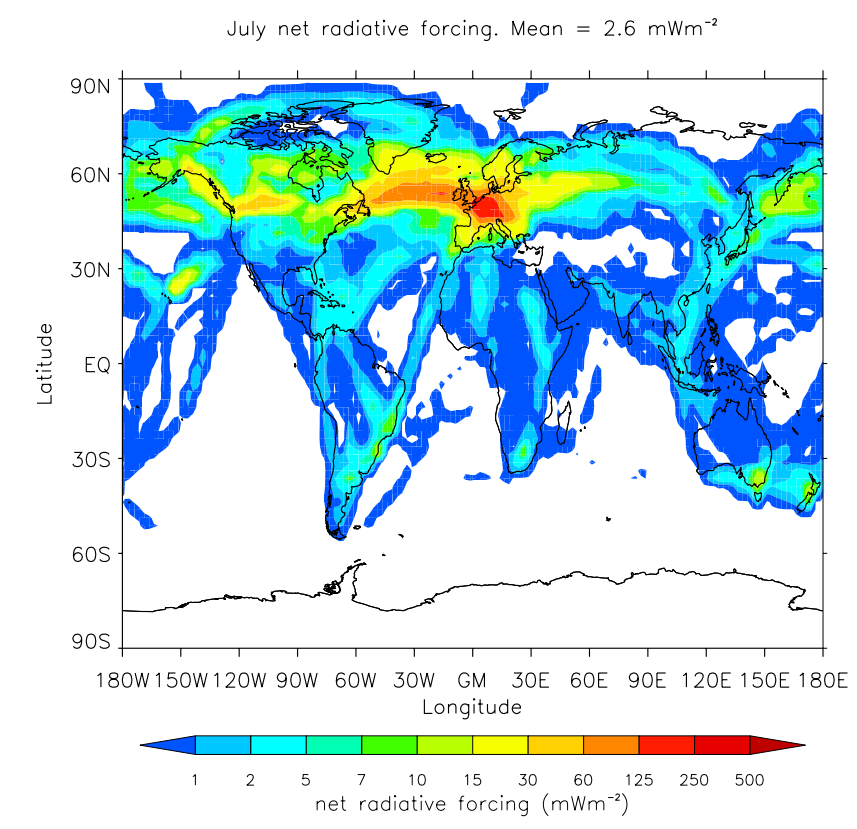

Fig. 3. Same as Fig. 1 but for July.

\section{Results}

The geographical distributions of the calculated contrail net RFs are shown in Figs. 2 and 3, with a global average of $7.6 \mathrm{~m} \mathrm{~W}^{-2}$ in January and $2.6 \mathrm{~m} \mathrm{~W}^{-2}$ in July. The maximum monthly mean of $360 \mathrm{~m} \mathrm{~W}^{-2}$ occurs over Northwest USA in January. The fact that the global mean CC in January is $0.078 \%$ compared to only $0.038 \%$ in July, partly explains the larger effect of contrails in January. Other factors, 


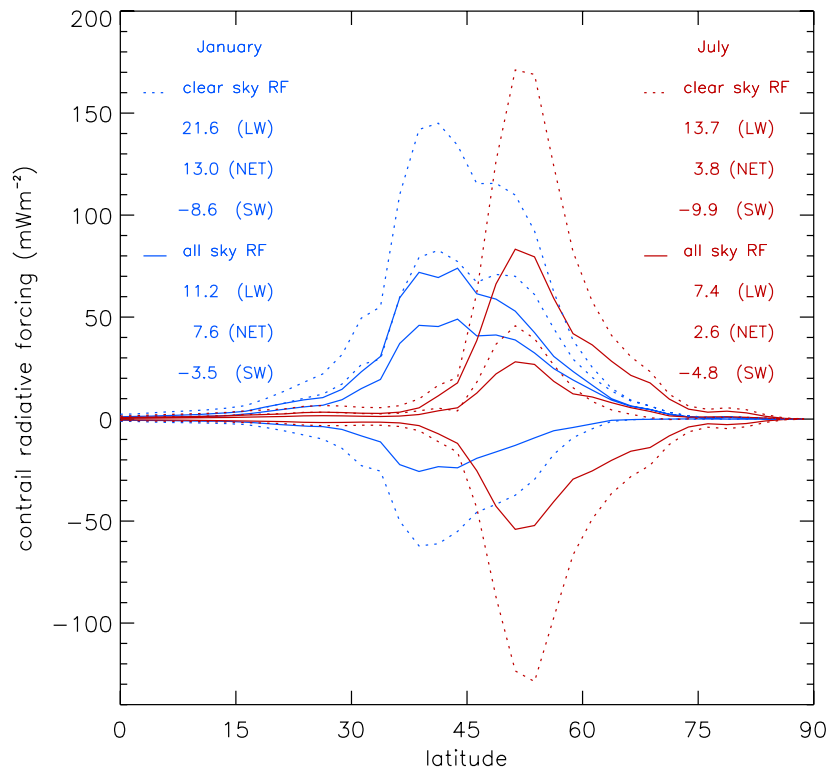

Fig. 4. January and July zonal contrail LW (uppermost dotted and solid lines), SW (lowermost dotted and solid lines), and net (middle dotted and solid lines) radiative forcings with natural clouds included (all sky) and excluded (clear sky). The numbers show the global average.

however, including the background meteorology, the albedo, the natural cloud cover and the temperature difference between the contrail and the emitting surface underneath it, also contribute to this seasonal variability, resulting in an enhanced weighted net contrail RF in January.

The impact of natural clouds on the calculated contrail RF is assessed by comparing modelled results for clouds being present or absent. The Northern Hemisphere's (NH) zonal RF profiles for the "all sky" and "clear sky" (contrails only) cases and their global means are presented in Fig. 4, showing that the presence of natural clouds reduces RF slightly more in the SW than in the LW, thereby somewhat reducing the net RF. Locally this is not always the case, as it can be seen in the July profiles at latitudes higher than $60^{\circ} \mathrm{N}$ : here the contrails' net RF is actually enhanced by natural clouds. This effect tends to occur over high latitude ice free regions, where contrails can show negative net RFs in the absence of other clouds. As can be seen in Fig. 4, however, the global mean always remains positive.

Natural clouds in the model are responsible for a reduction of around $40 \%$ in the annual contrail net RF, which contrasts with less than $10 \%$ reported in previous studies (e.g., Myhre et al., 2001; Stuber and Forster, 2007; Rädel and Shine, 2008). It is possible to obtain contrail net RF reductions as small as $11 \%$ from natural clouds in our model if random overlap is assumed, but we regard the maximumrandom overlap model to be more realistic in this context.

In order to assess the sensitivity of a contrail's RF to its altitude, while excluding any dependence on its horizontal ex-

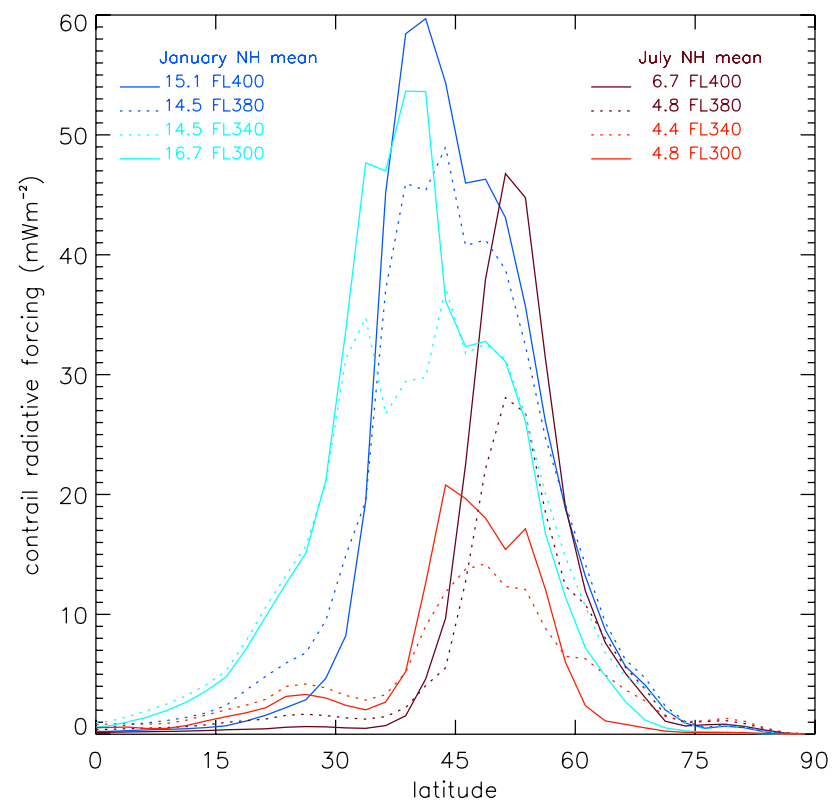

Fig. 5. January and July zonal mean contrail net RFs for cruise altitudes of 30000, 34000,38000 and $40000 \mathrm{ft}$ (FL300, FL340, FL380, and FL400 respectively). The numbers show the NH average.

tent, four pressure levels $(300,250,200$ and $150 \mathrm{hPa})$, representative of the cruise altitudes with significant $\mathrm{CC}$, are used. These pressure levels roughly correspond to flight levels FL300, FL340, FL380, and FL400 (i.e. altitudes of 30000 , 34000,38000 , and $40000 \mathrm{ft}$ ). The same CC is prescribed at these levels and their RFs are compared.

At middle latitudes in the $\mathrm{NH}$, where most traffic is concentrated, around $70 \%$ of the distance travelled by aircraft occurs between FL340 and FL380. This, together with the dependence of contrail formation on meteorological conditions, means that FL300 and FL400 would have a comparatively much smaller CC. The potential CC, defined as the fraction of the sky covered by contrails if traffic were present everywhere and all the time, can be negligible at these flight levels in some cases, for example for low latitude flights at FL300 in January and FL300 and FL340 in July. This is also the case for high latitude flights at FL400 in July. Despite the small likelihood of contrails being formed in these cases, the results of their radiative properties are still included for comparison purposes.

Figure 5 shows the zonal and mean net RFs for the $\mathrm{NH}$, which present markedly enhanced values for FL300 in January $\left(16.7 \mathrm{~m} \mathrm{~W}^{-2}\right)$ and FL400 in July $\left(6.7 \mathrm{~m} \mathrm{~W}^{-2}\right)$. Other cruise altitudes show more modest impacts in both months with values of around $14.5 \mathrm{~m} \mathrm{~W}^{-2}$ in January and around $4.5 \mathrm{~m} \mathrm{~W}^{-2}$ in July. These differences are related not only to the dependence of the contrail radiative properties on the contrail's altitude, and therefore on the ambient temperature, but also to the background conditions, i.e. 


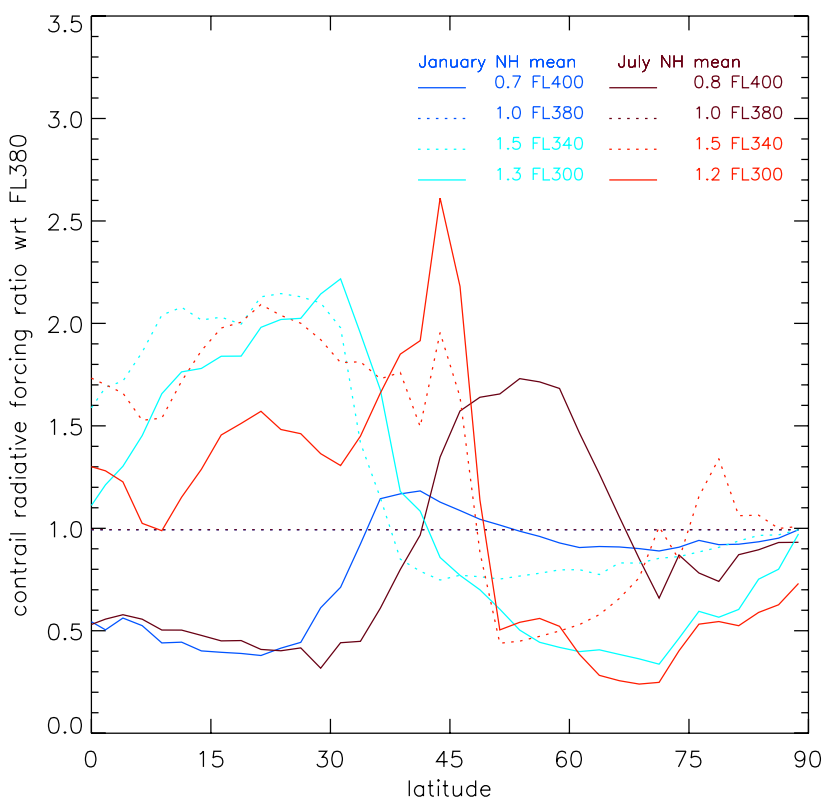

Fig. 6. January and July zonal net RF ratio for the cruise altitudes shown in Fig. 5 with respect to FL380. The numbers show the NH average.

meteorology, natural cloud cover, local albedo and the difference in temperature between the contrail's top and that of the clouds or the surface underneath. Despite the fact that FL340 and FL380 show similar global mean RFs for the two months, their zonal profiles show significant differences. These differences can be seen more clearly in Fig. 6, which shows the ratio of the RF calculated for different flight levels with respect to the RF estimated for FL380. The largest altitude sensitivity is predicted to occur at low latitudes, where the radiative impact of contrails decreases markedly with altitude. This behaviour changes at middle latitudes (at around $40-45^{\circ} \mathrm{N}$ ) in both months, where FL300 and FL340 show important reductions. Efficient strategies for contrail impact reductions must be based not only on the optical properties of contrails but also on the potential CC (not included here), which is beyond the scope of the present study, but should be considered together using mutually consistent models.

The OD of ice clouds is determined by their particle habit and their ice water path, defined as the IWC integrated over the vertical extent of the cloud. No climatology of contrail vertical thickness is available at present, but a range of values can be tested in order to assess the sensitivity of contrail $\mathrm{RF}$ to its OD. A case of a contrail with a maximum OD of 2.3 and a corresponding vertical thickness of $1 \mathrm{~km}$, was reported by Atlas and Wang (2010) based on Lidar retrievals; this value is used here as the upper bound for the possible range of contrails' vertical thickness while a lower bound of $220 \mathrm{~m}$ is chosen. The latter was used by Minnis et al. (1999) to approximate the RF of contrails by a single layer positioned at $200 \mathrm{hPa}$. We have confirmed the validity of this ap-

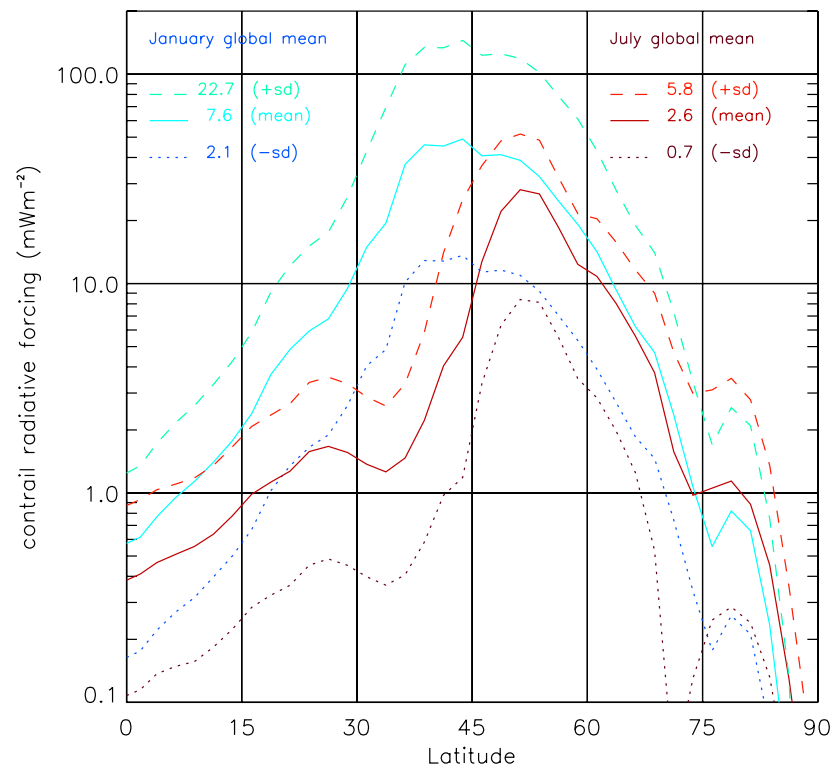

Fig. 7. January and July zonal contrail net radiative forcing for mean, upper standard deviation (+sd), and lower standard deviation (-sd) IWC assumptions at FL380 and $1000 \mathrm{~m}$ vertical depth. The numbers show the global average.

proximation in our model by comparing the results of a 3D distribution with those of the vertically integrated CC. This showed differences in the RF monthly averages of less than $10 \%$.

In order to assess the RF sensitivity to a contrail's IWC, three cases are compared. These cases are defined by the fitted curves to the mean, and to the lower and upper standard deviations calculated from Schiller et al.'s compilation, shown Fig. 1. The results, presented in Fig. 7, show a greater sensitivity in January than in July. This is a consequence of the greater sensitivity of the IWC to temperature observed in Fig. 1 at lower temperatures.

The dependence of the global mean RFs on the IWC is summarized in Table 1 . This shows the NH monthly mean $\mathrm{OD}$, the ice water path and the generalized size parameter, as well as their annual means. Here it should be noted that the average of January and July serves as a proxy for the annual mean. Both the OD and the net RF show a sensitivity to the IWC variability of at least an order of magnitude. The sensitivity to the contrails' vertical thickness, on the other hand, is only around a factor of 2, as it can be seen from the differences in the RF for $220 \mathrm{~m}$ and $1000 \mathrm{~m}$ physical depths with the same IWC.

The predicted range of $D_{g e}$ spans a factor of 2 , with a $D_{g e}$ of around $25 \mu \mathrm{m}$ being predicted over the $\mathrm{NH}$ if mean values for IWC are assumed; this value is similar to that $(23.5 \mu \mathrm{m})$ for the contrail PSD commonly assumed in off-line contrail studies (Strauss et al., 1997), showing that this PSD does not differ significantly from that of typical cirrus at contrail altitudes. Despite the significant variability in the predicted $D_{g e}$ 
observed in Table 1, the sensitivity of the RF to $\mathrm{D}_{\text {ge }}$ cannot be assessed independently of the IWC variability without inconsistent micro-physical assumptions.

\section{Discussion}

Off-line radiative transfer studies for contrails usually assume fixed OD values, between 0.1 and 0.5 , with a recent trend towards the lower end of this range. Representative OD values are normally derived from satellite data because of their large scale coverage, but the detection of persistent contrails by passive remote sensing instruments requires them to reach the detection thresholds for OD and horizontal extent while retaining their linear shape; this limitation may introduce biases into the physical and temporal properties derived statistically from satellite retrievals.

In the present study if the IWC variability is neglected, and only the vertical thickness is allowed to vary, the predicted range of mean annual global OD values [0.08, 0.32] for contrails between 220 and $1000 \mathrm{~m}$, matches the range of values commonly assumed in recent off-line studies. The results presented by Ponater et al. (2002), based on on-line contrail simulations, also fall within this range, as they reported an annual global mean OD of 0.15 for a $700 \mathrm{~m}$ thick contrail. Using the same vertical depth as was prescribed by the resolution of Ponater et al.'s model, the setup used here produces a global mean OD of 0.23 .

Ponater et al. reported a variability in global contrail OD that shows similarities with our findings. They predict maximum monthly values to be larger than the mean by an order of magnitude; this is confirmed in our study, but important differences with Ponater et al.'s results, however, occur on a regional level. Their predicted ODs over the USA show a large seasonal variability [0.04 to 0.25 ], whereas we find only a modest variability $[0.29-0.34](<20 \%$, assuming a $1000 \mathrm{~m}$ vertical thickness), in closer agreement with satellite retrievals by Palikonda et al. (2005), who reported a summer maximum 20-30\% greater than the February minimum.

Over the annual average, we find the mean OD over the USA to be similar to the NH average, while Europe shows values about $10 \%$ smaller. Ponater et al. similarly found thicker contrails over America but with a larger seasonal variability than in Europe. This contrasts with the our findings, in which contrails in Europe show a considerably broader seasonal variability, with the mean OD reaching values at least $50 \%$ larger in July than in January, resulting in contrails being optically thinner than over the USA during the winter but optically denser during the summer. Ponater et al.'s value of 0.06 falls outside the range predicted here for $\mathrm{Eu}-$ rope [0.07-0.28], but the satellite-retrieved value of 0.11 reported by Meyer et al. (2002) falls within it. The fact that the satellite estimate over Europe falls close to our lower bound, while Palikonda et al.'s satellite OD estimate over the USA $(0.27)$ falls closer to the upper bound of our range $[0.08,0.32]$ for that region, can be explained by the larger seasonal variability predicted over Europe. This variability translates into ODs being smaller than 0.2 during the winter, implying a reduced detectability by passive remote sensing instruments according to Kärcher et al. (2009) who, based on an analytical micro-physical cloud model, concluded that passive satellite remote strongly underestimate the ocurrence frequency of contrails with optical depths $<0.1-0.2$.

Kärcher et al. reported mean contrail-cirrus visible ODs of between 0.05 and 0.5 over the USA; this range is slightly broader than the NH range found here [0.08-0.32] for mean IWCs. In a later study, Kärcher et al. (2010) estimated the mean OD at $250 \mathrm{hPa}$ over the USA to be 0.125 , which also falls within the range obtained here for mean IWCs. Both, theoretical simulations and field measurements of contrails include maximum ODs significantly larger than the upper bound of this range; Ponater et al. reported monthly maximum ODs over the USA as large as 3, while Atlas and Wang's lidar retrievals detected a $1 \mathrm{~km}$ thick persistent linear contrail with an OD around 2.3.

Larger optical depths than those obtained here for mean IWC assumptions have been used in previous studies. Minnis et al. (1999) performed off-line contrail RF calculations assuming fixed ODs between 0.1 and 0.5 and also included a case with a variable contrail IWC. The latter produced a $\mathrm{RF}$ of $10 \mathrm{~m} \mathrm{Wm}^{-2}$; this value falls very close to their result $\left(8 \mathrm{~m} \mathrm{Wm}^{-2}\right)$ for a fixed OD of 0.1 . This OD is similar to the one obtained here $(0.08)$ for the same physical depth assuming mean IWC values, although the corresponding RF calculated by Minnis et al. is larger than our value $\left(2 \mathrm{~m} \mathrm{Wm}^{-2}\right)$ by a factor of 2.5, bearing in mind that their global mean CC is almost twice as large as the one used here. This difference in the calculated RF is similar to that expected from model discrepancies; in a recent intercomparison of contrail global RF models (Myhre et al., 2001) found differences of around a factor of 2 for an assumed $1 \%$ homogeneous global CC, and slightly smaller differences for a realistic cover. But the difference between the contrail RFs obtained here and in Minnis et al. assuming a variable IWC is significantly reduced if, as in Minnis et al., we replace our cloud maximum overlap assumption for a random overlap, in which case our results increase by a factor of 3 .

By linearly scaling up the RF of year 1992 based on the traffic increase and excluding any climate change effects, a range of RFs between 1.0 and $66.2 \mathrm{~m} \mathrm{Wm}^{-2}$ is obtained for year 2005 (see Table 1), based on a scaling factor of 1.7 that accounts for the increase in travelled distance between the two years. A factor of 2.7 is applied to the upper bound of each IWC regime in order to allow for the uncertainty in the estimated $\mathrm{CC}$, based on the correction introduced in Kärcher et al. (2010). The mean IWC assumption produces a RF range [ 3.4 to $23.4 \mathrm{~m} \mathrm{Wm}^{-2}$ ] that is similar to the values found in the recent literature. IPCC's best estimate of $10.0 \mathrm{~m} \mathrm{Wm}^{-2}$ falls within this range, as do more recent estimates, which tend to be smaller than that of the IPCC (2007) 
Table 1. Global mean top-of-the-atmosphere shortwave (SW), long-wave (LW), and net contrail radiative forcing $\left(\mathrm{m} \mathrm{W} \mathrm{m}^{-2}\right)$ for the three IWC assumptions (mean, upper and lower standard deviation). The weighted net RF (per \% contrail cover) is also included. The annual mean global contrail cover (CC) is $0.047 \%$, as calculated in the TRADEOFF inventory of aircraft flown distance for the year 1992 and scaled up CC values for year 2005 and a further factor of 2.7 scale up to allow for CC uncertainties. The mean optical depth (OD), generalized size ( $D_{\mathrm{ge}}$ in $\mu \mathrm{m}$ ), and ice water path (IWP in $\mathrm{gm}^{-2}$ ) correspond to the $\mathrm{NH}$ averages.

\begin{tabular}{cccccccrrrr}
\hline IWC & Month & OD & Dge & IWP & SW & LW & $\begin{array}{r}\text { Net } \\
1992\end{array}$ & $\begin{array}{r}\text { Net } \\
1992 \\
\%^{-1}\end{array}$ & $\begin{array}{r}\text { Net } \\
2005\end{array}$ & $\begin{array}{r}\text { Net } \\
\text { (CC X 2005 }\end{array}$ \\
\hline$-1 \sigma$ & & & & & & & & & & \\
$220 \mathrm{~m}$ & Jan & 0.02 & 13.9 & 0.30 & -0.5 & 1.4 & 0.9 & 10.0 & & \\
& Jul & 0.03 & 14.2 & 0.38 & -0.6 & 0.8 & 0.3 & 8.4 & & \\
\hline$-1 \sigma$ & Jnnual & 0.02 & 14.0 & 0.34 & -0.5 & 1.1 & 0.6 & 9.2 & 1.0 & \\
$1000 \mathrm{~m}$ & Jul & 0.08 & 18.5 & 0.61 & -1.2 & 3.3 & 2.1 & 23.0 & & \\
& Annual & 0.08 & 19.1 & 0.70 & -1.3 & 2.7 & 1.4 & 22.6 & & \\
\hline Mean & Jan & 0.07 & 23.3 & 1.6 & -1.5 & 4.5 & 3.0 & 33.4 & & \\
$220 \mathrm{~m}$ & Jul & 0.09 & 24.0 & 2.0 & -1.7 & 2.7 & 1.0 & 29.9 & & \\
& Annual & 0.08 & 23.2 & 1.7 & -1.6 & 3.6 & 2.0 & 31.6 & 3.4 & \\
\hline Mean & Jan & 0.28 & 26.2 & 3.2 & -3.6 & 11.2 & 7.6 & 82.4 & & \\
$1000 \mathrm{~m}$ & Jul & 0.36 & 26.4 & 4.2 & -4.8 & 7.4 & 2.6 & 80.6 & & \\
& Annual & 0.32 & 26.3 & 3.7 & -4.2 & 9.3 & 5.1 & 81.5 & & 23.4 \\
\hline$+1 \sigma$ & Jan & 0.29 & 24.4 & 6.8 & -4.5 & 15.3 & 10.8 & 118.9 & & \\
$220 \mathrm{~m}$ & Jul & 0.37 & 24.6 & 8.8 & -6.3 & 9.7 & 3.4 & 107.7 & & \\
& Annual & 0.33 & 24.5 & 7.8 & -5.4 & 12.5 & 7.1 & 113.3 & 12.1 & \\
\hline$+1 \sigma$ & Jan & 1.12 & 27.9 & 14.0 & -8.2 & 30.8 & 22.7 & 217.7 & & \\
$1000 \mathrm{~m}$ & Jul & 1.39 & 29.2 & 18.2 & -13.3 & 19.1 & 5.8 & 187.5 & & \\
& Annual & 1.26 & 28.6 & 16.1 & -10.8 & 25.0 & 14.3 & 202.6 & & \\
\hline
\end{tabular}

in response to the mentioned trend towards lower end [0.1 to 0.3 ] of the range of ODs retrieved by satellite.

\section{Conclusions}

Assuming that the IWC of persistent aged contrails varies with temperature similarly to natural cirrus leads to a larger uncertainty range of contrail RF than has been predicted by satellite and theoretical studies. The contrail vertical thickness range $[220-1000 \mathrm{~m}]$ assumed here for a single contrail layer at $38000 \mathrm{ft}$, provided a range of ODs [0.08-0.32] that supports the range of values assumed in recent off-line studies. This range, based on mean IWC values produced RFs between 3.4 and $23.4 \mathrm{~m} \mathrm{Wm}^{-2}$ for year 2005, and provided a seasonal and regional variability in good agreement with satellite OD retrievals.

A range of RFs between 1 and $66 \mathrm{~m} \mathrm{Wm}^{-2}$ is obtained if one standard deviation IWC variability is assumed, translating into a wider range of radiative forcings from linear contrails than that reported in previous studies, including IPCC's [ 3 to $30 \mathrm{~m} \mathrm{Wm}^{-2}$ ]. A sensitivity on vertical thickness of around a factor of 2 is found for the calculated contrail RF and OD, compared to an IWC dependence that exceeds one order of magnitude.

For a fixed CC, the contrail's RF showed a modest dependence in January at heavily trafficked latitudes; but the optical properties produced significant RF reductions from FL400 at low latitudes and from FL300 and FL340 from latitudes greater than $50^{\circ} \mathrm{N}$.

Acknowledgements. This work was supported by the United Kingdom Department for Transport. The authors wish to thank a number of people for providing us with the data used in this study. Christine Frömming for providing the contrail cover distribution data calculated during the TRADEOFF project. (TRADEOFF was a project in the European Fifth Framework Programme, http://www.iac.ethz.ch/tradeoff/); Prof. Piers Forster for the climatology of the monthly atmospheric composition, cloud cover and surface albedo, and Dr. Anthony Baran for the hexagonal prisms database. We thank our colleague, Dr Michael Bennett for valuable discussions and his help to improve the readability of the manuscript. We also thank two anonymous referees and the editor for their helpful comments and suggestions.

Edited by: P. Spichtinger 


\section{References}

Atlas, D. and Wang, Z.: Contrails of small and very large optical depth, J. Atmos. Sci., 67, 3065-3073, doi:10.1175/2010JAS3403.1, 2010.

Baran, A. J., Havemann, S., and Mackowski, D.: A database of hexagonal column optical properties for wavelengths ranging between 0.2 microns to 30 microns produced for ANNEX 7, Contract No. 4b/3/02, DEFRA, UK, 2001.

Edwards J. M. and Slingo, A.: Studies with a flexible new radiation code. I: Choosing a configuration for a large-scale model, Q. J. Roy. Meteor. Soc., 122, 689-719, doi:10.1256/smsqj.53106, 1996.

Fichter, C., Marquart S., Sausen R., and Lee D. S.: The impact of cruise altitude on contrails and related radiative forcing, Meteorol. Z., 14, 563-572. doi:10.1127/0941-2948/2005/0048, 2005.

Fu, Q.: An accurate parameterization of the solar radiative properties of cirrus clouds for climate models, J. Climate, 9, 20582082, 1996.

Fu, Q., Yang, P., and Sun, W. B.: An accurate parameterization of the infrared radiative properties of cirrus clouds for climate models. J. Climate, 11, 2223-2237, 1998.

Heymsfield, A. J.: On measurements of small ice particles in clouds, Geophys. Res. Lett., 34, L23812, doi:10.1029/2007GL030951, 2007.

IPCC: Aviation and the global atmosphere - A special report of IPCC working groups I and III, Intergovernmental Panel on Climate Change, edited by: Penner, J. E., Lister, D. H., Griggs, D. J., Dokken, D. J., McFarland, M.: Cambridge University Press, Cambridge, UK and New York, NY, USA, 365 pp., 1999.

IPCC: Contribution of Working Group I to the Fourth Assessment Report of the Intergovernmental Panel on Climate Change, Solomon, S., Qin, D., Manning, M., Chen, Z., Marquis, M., Averyt, K. B., Tignor, M., and Miller, H. L., Cambridge University Press, Cambridge, United Kingdom and New York, NY, USA, 996 pp., 2007.

Jensen, E. J. and Toon O. B.: The potential impact of soot particles from aircraft exhaust on cirrus clouds, Geophys. Res. Lett., 24, 249-252, doi:10.1029/96GL03235, 1997.

Jensen, E. J., Lawson, P., Baker, B., Pilson, B., Mo, Q., Heymsfield, A. J., Bansemer, A., Bui, T. P., McGill, M., Hlavka, D., Heymsfield, G., Platnick, S., Arnold, G. T., and Tanelli, S.: On the importance of small ice crystals in tropical anvil cirrus, Atmos. Chem. Phys., 9, 5519-5537, doi:10.5194/acp-9-5519-2009, 2009.

Kärcher, B., Burkhardt, U., Unterstrasser, S., and Minnis, P.: Factors controlling contrail cirrus optical depth, Atmos. Chem. Phys., 9, 6229-6254, doi:10.5194/acp-9-6229-2009, 2009.

Kärcher, B., Burkhardt, U., Ponater, M., and Fromming, C.: Importance of representing optical depth variability for estimates of global line-shaped contrail radiative forcing, Proc. Natl. Acad. Sci. USA, 107, 19181-19184, doi:10.1073/pnas.1005555107, 2010.

Krämer, M., Schiller, C., Afchine, A., Bauer, R., Gensch, I., Mangold, A., Schlicht, S., Spelten, N., Sitnikov, N., Borrmann, S., de Reus, M., and Spichtinger, P.: Ice supersaturations and cirrus cloud crystal numbers, Atmos. Chem. Phys., 9, 3505-3522, doi:10.5194/acp-9-3505-2009, 2009

Li, Z. and Leighton, H.: Global Climatologies of Solar Radiation Budgets at the Surface and in the Atmosphere From
5 Years of ERBE Data, J. Geophys. Res., 98, 4919-4930, doi:10.1029/93JD00003, 1993.

Marquart, S., Ponater M., Mager F., and Sausen R.:Future development of contrail cover, optical depth, and radiative forcing: impacts of increasing air traffic and climate change. J. Climate, 16, 2890-2904, 2003.

McFarquhar, G. M. and Heymsfield, A. J.: Parameterization of Tropical Cirrus Ice Crystal Size Distributions and Implications for Radiative Transfer: Results from CEPEX. J. Atmos. Sci., 54, 2187-2200, 1997.

McFarquhar, G. M., Um, J., Freer, M., Baumgardner, D., Kok, G. L., and Mace, G.: Importance of small ice crystals to cirrus properties: Observations from the Tropical Warm Pool International Cloud Experiment (TWP-ICE), Geophys. Res. Lett., 34, L13803, doi:10.1029/2007GL029865, 2007.

Meerkötter, R., Schumann, U., Doelling, D. R., Minnis, P., Nakajima, T., and Tsushima, Y.: Radiative Forcing by Contrails. Ann. Geophys., 17, 1080-1094, doi:10.1007/s00585-999-10807, 1999.

Minnis P., Schumann, U., Doelling, D. R., Gierens, K., and Fahey, D.: Global distribution of contrail radiative forcing, Geophys. Res. Lett., 26, 1853-1856, doi:10.1029/1999GL900358, 1999.

Minnis, P., Ayers, J. K., Palikonda, R., and Phan, D.: Contrails, Cirrus Trends, and Climate, J. Climate, 17, 1671-1685, 2004.

Myhre, G. and Stordal, F.: On the tradeoff of the solar and thermal infrared radiative impact of contrails, Geophys. Res. Lett., 28, 3119-3122, doi:10.1029/2001GL013193, 2001.

Myhre, G., Kvalevåg, M., Shine, K. P., Rädel, G., Cook, J.., Clark, H., Karcher F., Markowicz, K., Balkanski, Y., Ponater, M., Forster, P., Rap, A., De Leon, R. R.: Quantifying the uncertainty associated with the radiative forcing of stratospheric water vapour and contrails, Meteorol. Z., 18, 585-596, 2009.

Meyer, R., Mannstein, H., Meerkötter, R., Schumann, U., and Wendling, P.: Regional radiative forcing by line-shaped contrails derived from satellite data, J. Geophys. Res., 107, 4104, doi:10.1029/2001JD000426, 2002.

Palikonda, R., Minnis, P., Duda, D. P., and Mannstein, H.: Contrail coverage derived from 2001 AVHRR data over the continental United States of America and surrounding areas, Meteorol. Z., 14, 525-536, doi:10.1127/0941-2948/2005/0051, 2005.

Poellot, M. R., Arnott, W. P., and Hallett, J.: In situ observations of contrail microphysics and implications for their radiative impact, J. Geophys. Res., 104, 12077-12084, doi:10.1029/1999JD900109, 1999.

Ponater, M., Marquart, S., and Sausen, R.: Contrails in a comprehensive global climate model: Parameterization and radiative forcing results, J. Geophys. Res., 107, 4164, doi:10.1029/2001JD000429, 2002.

Rädel, G. and Shine K. P.: Radiative forcing by persistent contrails and its dependence on cruise altitudes, J. Geophys. Res., 113, D07105, doi:10.1029/2007JD009117, 2008.

Rossow, W. B. and Schiffer, R. A.: Advances in understanding clouds from ISCCP, B. Am. Meteorol. Soc., 80, 2261-2288, 1999.

Schäuble, D., Voigt, C., Kärcher, B., Stock, P., Schlager, H., Krämer, M., Schiller, C., Bauer, R., Spelten, N., de Reus, M., Szakáll, M., Borrmann, S., Weers, U., and Peter, Th.: Airborne measurements of the nitric acid partitioning in persistent contrails, Atmos. Chem. Phys., 9, 8189-8197, doi:10.5194/acp-9-8189-2009, 
2009.

Schiller, C., Krämer, M., Afchine, A., and Spelten, N.: Ice water content of Arctic, midlatitude, and tropical cirrus, J. Geophys. Res., 113, D24208, doi:10.1029/2008JD010342, 2008.

Schumann, U., Mayer, B., Gierens, K., Unterstrasser, S., Jessberger, P., Petzold, A., Voigt, C., and Gayet, J.-F.: Effective Radius of Ice Particles in Cirrus and Contrails. J. Atmos. Sci., 68, 300-321, doi:10.1175/2010JAS3562.1, 2011.

Simmons, A. and Gibson, J.: The ERA-40 Project Plan, ERA-40 Proj. Rep. Ser., 1, 2000.

Strauss, B., Meerkötter, R., Wissinger, B., Wendling, P., and Hess, M.: On the regional climatic impact of contrails: microphysical and radiative properties of contrails and natural cirrus clouds, Ann. Geophys., 15, 1457-1467, doi:10.1007/s00585-997-14574, 1997.
Stuber, N. and Forster, P.: The impact of diurnal variations of air traffic on contrail radiative forcing, Atmos. Chem. Phys., 7, 3153-3162, doi:10.5194/acp-7-3153-2007, 2007.

Wyser, K. and Ström, J.: A possible change in cloud radiative forcing due to aircraft exhaust, Geophys. Res. Lett., 25, 1673-1676, doi:10.1029/98GL51091, 1998.

Yang, P., Liou, K. N., Wyser, K., and Mitchell, D.: Parameterization of the scattering and absorption properties of individual ice crystals, J. Geophys. Res., 105(D4), 4699-4718, doi:10.1029/1999JD900755, 2000. 